\title{
TOWARDS A REMOTE SENSING BASED ASSESSMENT OF LAND SUSCEPTIBILITY TO DEGRADATION: EXAMINING SEASONAL VARIATION IN LAND USE-LAND COVER FOR MODELLING LAND DEGRADATION IN A SEMI-ARID CONTEXT
}

\author{
Gofamodimo Mashame*,a, Felicia Akinyemi ${ }^{\mathrm{a}}$

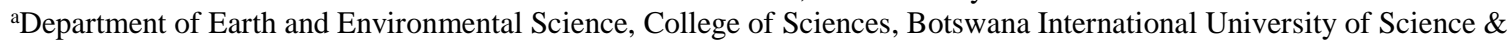 \\ Technology, Private Bag 16, Palapye, Botswana-gmashame@gmail.com, felicia.akinyemi@ gmail.com
}

KEY WORDS: Land Use-Land Cover, Land Degradation, Remote Sensing, LANDSAT, Semi-arid region, Supervised Classification, Maximum Likelihood, Land Change Modeler.

\begin{abstract}
:
Land degradation (LD) is among the major environmental and anthropogenic problems driven by land use-land cover (LULC) and climate change worldwide. For example, poor LULC practises such as deforestation, livestock overstocking, overgrazing and arable land use intensification on steep slopes disturbs the soil structure leaving the land susceptible to water erosion, a type of physical land degradation. Land degradation related problems exist in Sub-Saharan African countries such as Botswana which is semi-arid in nature. LULC and LD linkage information is still missing in many semi-arid regions worldwide. Mapping seasonal LULC is therefore very important in understanding LULC and LD linkages. This study assesses the impact of seasonal LULC variation on LD utilizing Remote Sensing (RS) techniques for Palapye region in Central District, Botswana. LULC classes for the dry and rainy seasons were classified using LANDSAT 8 images at Level I according to the Food and Agriculture Organization (FAO) International Organization of Standardization (ISO) code 19144. Level I consists of 10 LULC classes. The seasonal variations in LULC are further related to LD susceptibility in the semi-arid context. The results suggest that about $985 \mathrm{~km}^{2}(22 \%)$ of the study area is susceptible to LD by water, major LULC types affected include: cropland, paved/rocky material, bare land, built-up area, mining area, and water body. Land degradation by water susceptibility due to seasonal land use-land cover variations is highest in the east of the study area where there is high cropland to bare land conversion.
\end{abstract}

\section{INTRODUCTION}

Land degradation (LD) is among the major environmental and anthropogenic problems driven by change in land useland cover (LULC) and climate change worldwide especially in semi-arid regions (Li et al., 2015; Utuk and Daniel, 2015). Research conducted by Olagunju (2015) supports the claim that LD is accelerated by climate variability and poor land use (LU) practises in semi-arid regions. Approximately $16-40 \%$ of the global farmlands have already been exposed to LD and 129 million hectares of forest have been lost worldwide due to the increase in human activities such as agricultural expansion (Chappell and Lavalle, 2011; Global Forest Resources Assessment, 2015). Moreover $70 \%$ of dry lands in Africa, South America and Asia are affected by LD which involves: $30 \%$ of irrigated arid lands, $47 \%$ of rain-fed cultivation and $73 \%$ of vegetation (Utuk and Daniel, 2015) and Africa has the highest net of forest loss recording 2.8 million hectares lost annually (Food and Agriculture Organization, 2015). LD has occurred in $41 \%$ of Africa's land in arid regions inhabited by over 268 million people, particularly in Sub-Saharan Africa (Mohammed, 2013).

Consider the major additional environmental problems emanating from poor LULC practises such as deforestation, overstocking, overgrazing and agricultural intensification on arable lands and steep slopes which increase susceptibility of topsoils to erosion, i.e. LD by water (Briassoullis, 2000; Mirzabaev et al. 2016). Additive anthropogenic pressures include: commerce, mining, industrialization, urbanization, among others (Deka et al, 2014). From the $20^{\text {th }}$ to the $21^{\text {st }}$ century, a major impact of land use change is the decline in food production due to increase in unproductive bare lands. The Global Assessment of Human Induced Soil Degradation (GLASOD) study found that 1.97 billion hectares (ha) of global agricultural lands are subjected to extreme soil loss by water (Bhattarai, 2013) and every year soil degradation increases by 5-7 million hectares worldwide (International Atomic Energy Agency, 2014).

Some major types of LD and driving processes identified in semi-arid Botswana are soil erosion, tillage erosion, soil salinization, water stress, forest fires, retreat of grass cover and perennial grasses, bush encroachment, reactivation of sand dunes (Favretto et al., 2014; Kairis et al., 2014). Favretto et al. (2014), identified rangeland ecosystem service benefits such as food, fuel, construction material, ground water, genetic diversity, climate regulation, recreation and spiritual inspiration in the Kalahari. The study assessed the trade-offs associated with delivering these services in communal grazing lands, private cattle ranching, game ranching and in Wildlife Management Areas.

Although studies are beginning to imply a link between LULC and LD, explicit information of such linkages is still scarce in the literature for many semi-arid regions. This study contributes to filling this knowledge gap by examining and mapping seasonal LULC in order to decipher the influence of seasonal changes in LULC might have on land susceptibility to LD, with particular focus on soil erosion by water. Kairis et al. (2014), found soil erosion to be an important land degradation and desertification process in the Boteti area of 
Botswana. This study is therefore very important in understanding LULC and LD linkages in semi-arid contexts. In addition, it aids our understanding of some anthropogenic and environmental issues associated with LD (Kuldeep and Kamlesh, 2011).

Chen et al (2015) stated that Global Land Cover (GLC) information available have been scrutinized by many researchers and global communities worldwide such as the International Society for Photogrammetry and Remote Sensing (ISPRS) and Group on Earth Observation (GEO) due to poor quality, accuracy and lacking seasonal LULC variation maps. Fine resolution LULC information representative of the trend of local anthropogenic activities and the physical environment using best suited classification system is still missing in many semi-arid countries (Brown et al, 2015). Therefore assessing seasonal LULC variation as a factor of LD is vital for better planning, decision making and sustainable land management from local to global scale.

Remote Sensing (RS) is the only tool that efficiently provides detailed LULC data wherever on the globe with high object revisit time hence supporting monitoring of environmental and anthropogenic occasions such as LULC variation and LD linkage (French Scientific Committee on Desertification, 2005; Hansen et al, 2013). RS has immense advantages because satellites in space can capture larger areas in a cost effective, homogeneous, repetitive and systematic fashion around the globe (French Scientific Committee on Desertification, 2005). Remotely sensed satellite images have long been appreciated in mapping and analyzing LD factors such as soil erodibility, rainfall erosivity, slope length, slope direction, LULC etc. Multi-temporal satellite images provide the base to derive seasonal LULC maps at different spatial resolutions for modelling LD using RS mapping and modelling methods.

RS satellite platforms carry sensors from which energy reflected by earth surface features is recorded as electromagnetic waves (bands) from which information can be gathered. For that matter, different satellites have different sensors with different applications. RS satellite sensors store information of reflected energy from ground objects as picture elements (pixels) which would then be produced as aerial images either as soft copy or analogue format. A RS system can be used to produce seasonal LULC information to fight LD and it also enables monitoring LD in the future to guard against risk factors and support decision making in defining conservation measures and assessing their impacts. According to the Union of Concerned Scientists (UCS) (2015) there are many RS satellites orbiting the earth presently for monitoring environmental and anthropogenic events. Examples of these optical satellites are the following: LANDSAT, Quickbird, High Resolution Visible (HRV), Satellite Pour l'Observation de la Terre (SPOT), and IKONOS are mostly used nowadays for mapping LULC (Magee, 2011, Murayama et al, 2015). However, LANDSAT provides the longest medium resolution satellite data since its launch in 1972 (GISGeography, 2015) and data is available for free from the United States Geological Survey Website (USGS) (earthexplorer.usgs.gov/).
Seasonal LULC information can be derived from earth observation satellite images such as LANDSAT images at medium spatial resolution at different times for any place on earth using RS classification methods. Remote sensing based analysis and mapping of LULC is very appropriate for semi-arid Botswana due to its large geographic expanse $\left(582,000 \mathrm{~km}^{2}\right)$. It is described as one of the most desertified countries in Sub-Saharan Africa (Barrow, 1991). Moreover, LD in Botswana threatens food security because arable land accounts for only $5 \%$ of Botswana's land area which is inhabited by over 2 million people (Statistics Botswana, 2014). The focus of this study on the Palapye area is also appropriate as it is an example of a LD prone area in Botswana.

\section{MATERIALS AND METHODS}

The specific objectives of this study are to: 1) identify and map major LULC types for the dry and rainy seasons, 2) examine seasonal variations in LULC types, and, 3) establish LULC linkages to LD in the reference year, i.e. 2014. The major research question of interest in the study is, 'What are the seasonal variations in LULC types susceptible to LD in the study area?' on the premise that LULC types with exposure of top soils and/bare lands such as croplands are most susceptible to soil erosion by water.

\subsection{Study Location and Description}

Palapye, Central District, Botswana is the study location for seasonal land use-land change in relation to land degradation by water, other villages within the proximity such as Maunatlala, Lerala, Lesenepole, Gootau, Lecheng, Kgagodi, Mogapinyana and the historical Old Palapye area are also included (Refer to Figure 1).

Palapye is regarded as the fastest developing village in Africa (Botswana Guardian, 2014). The 2011 population census results put Palapye at 36211 having recorded an annual increase of 3.25 percent from 26293 ten years earlier (Statistics Botswana, 2014). Palapye is endowed with world class hotels, lodges, camp sites, shops, banks, manufacturing industries to provide residents, tourists and travellers with much needed services. However, majority of the study area is utilized for arable and pastoral farming. The study region covers approximately $4,479 \mathrm{~km}^{2}$ represented by the following geographical coordinates: A (492403.670, 7534369.134) metres, B (581956.143, 7530015.889) metres, C( 579572.223, 7480160.866) metres, $\mathrm{D}(489294.209$, 7485654.247) metres in WGS 84 UTM 35S coordinate system. (See Figure 1).

Notable land use-land cover areas in Palapye are shown in Figure 1 which include: Morupule Coal Mine, the newly constructed Botswana International University of Science and Technology (BIUST), bare lands in patches of white, Bonwakatlhako dam in blue, vegetation in red, rocky outcrop in cyan, built-up area in light cyan and cropland in light green. The vegetation type in Palapye is mainly savannah and shrub land with acacia tortillas and mopane colophospermum being dominant tree species. 


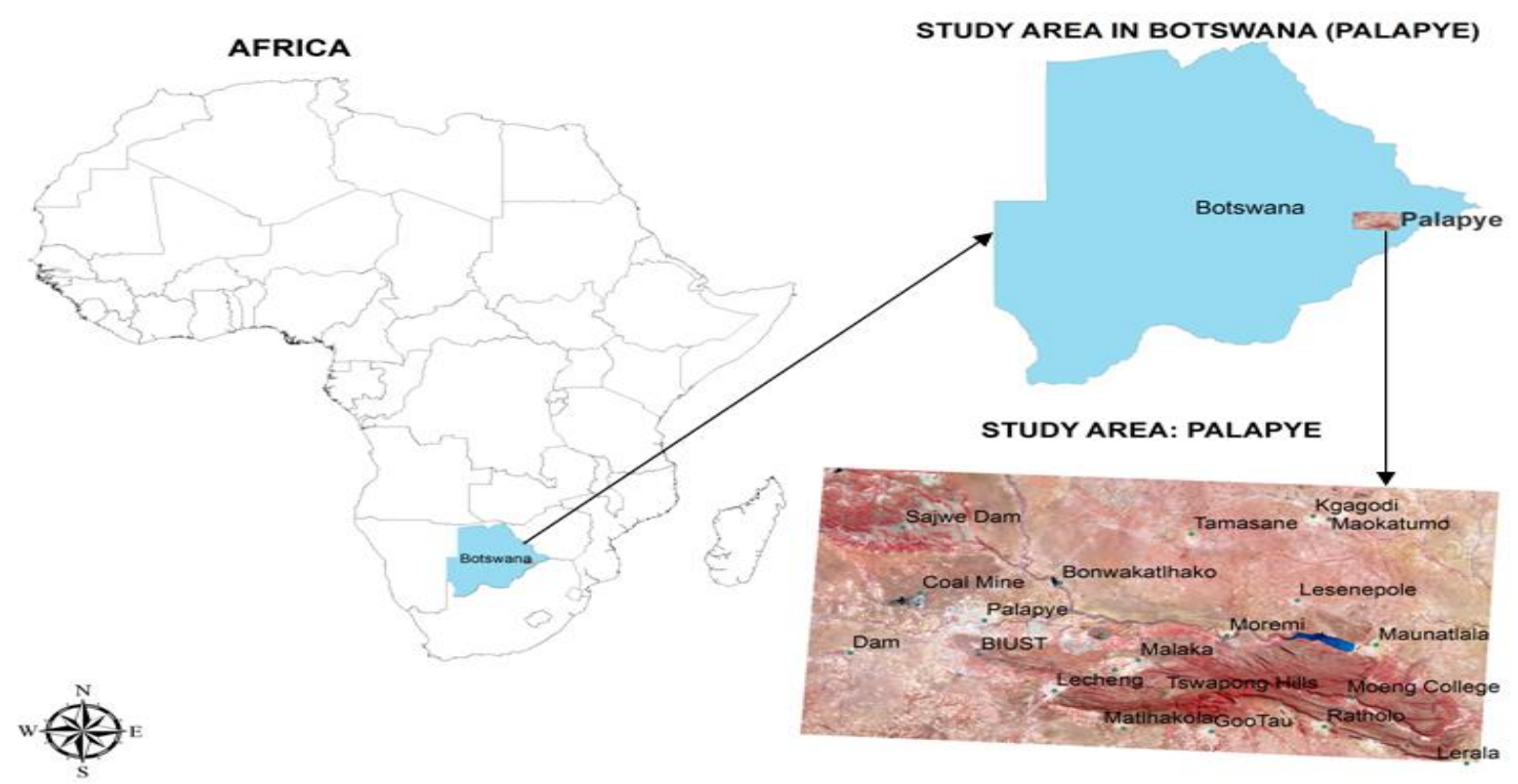

Figure 1: Location of the study area, semi-arid Palapye region in Botswana

\subsection{Data}

The $30 \mathrm{~m}$ spatial resolution LANDSAT 8 satellite data for USGS website (http://earthexplorer.usgs.gov) for Palapye the 2014 dry and rainy seasons were downloaded from the area (see Table 1).

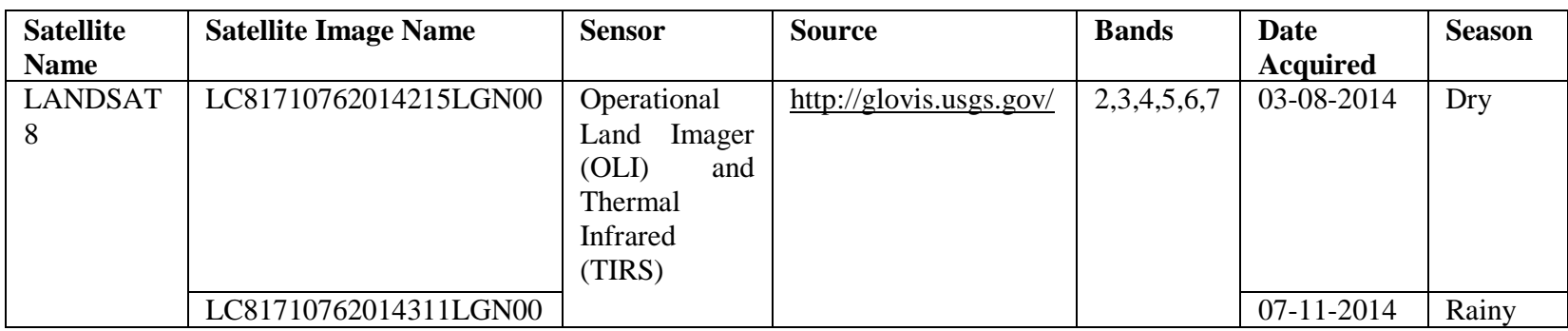

Table 1: Details about $30 \mathrm{~m}$ spatial resolution LANDSAT 8 image data used in the study

\subsection{Methods}

Seasonal LULC maps were classified from LANDSAT 8 (Operational Land Imager sensor) images at $30 \mathrm{~m}$ for 2014 dry and rainy season using the following RS classification/mapping procedures: classification scheme development, image pre-processing, classification, validation, change analysis and post classification for land degradation susceptibility as described below.

\subsubsection{LULC classification scheme:}

The FAO ISO 19144 classification system for land cover mapping designed by the Food and Agriculture Organization (FAO) was used for this study because it is the only standardized classification system for land cover mapping (Di Gregorio, 2005). LULC classes were classified at Level I. Level I is a generalized level consisting of 10 LULC classes as follows: Water body, Bare land, Forest, Savannah, Shrub land, Grass land, Built-up area, Cropland, Paved/Rocky Material, and Mining Area.

\subsubsection{Satellite image pre-processing:}

Satellite image pre-processing methods applied include data import to IMAGINE (IMG) format, band stacking, radiometric correction, registration and reprojection.

LANDSAT 8 images were geo-referenced pixel per pixel to curb false changes in seasonal land useland cover change detection using Georeferencing tool in ArcGIS 10.3. LANDSAT 8 images were delivered from USGS website in WGS 84 UTM $35 \mathrm{~N}$ for Palapye region, but since Palapye is in the southern hemisphere the images were re-projected to WGS 84 UTM 35S. Radiometric correction was applied to improve image quality using image enhancement technique. In this case histogram equalization technique was used and standard deviation set to 1 .

\subsubsection{Satellite image classification:}

Supervised classification method was used in conjunction with the maximum likelihood classifier to sort image pixels because the method 
utilizes the mean, variance, covariance of training sites digital numbers (Murtaza and Romshoo, 2014). Supervised classification was done on LANDSAT images by creating training sites of unique LULC classes with distinct pixel values/signatures to ensure class separability and classification was executed by maximum likelihood parametric rule. A 7 by 7 neighborhood filter was applied to remove noise in seasonal LULC maps.

\subsubsection{Seasonal LULC map validation:}

Stratified sampling points for validating both seasonal LULC maps of 2014 generated were 202 and 204 for dry and rainy season LULC maps respectively. The criterion for sampling was based on the accessibility of points in the real world, i.e. proximity to the road and settlements was considered. The vector shapefile consisting of settlements was intersected with that of roads for the Palapye area and both datasets were buffered using a radius of $1 \mathrm{~km}$. Stratified samples of reference points for ground truthing were then generated. The overall accuracy for 2014 dry and rainy season LULC are $88.12 \%$ and $85.29 \%$ respectively (see Table $1 \& 2$ ).
Stratification is based on a balanced estimation of points in which the samples are equally spaced in a study area, and also weighted mean can be applied to approximate the accuracy of points not sampled (Puertas et al, 2013). Stratified sampling is designed in a way in which points on LULC maps are sampled at equal spaces and for equal samples. However, strata for homogeneous LULC classes such as water body and bare land does not matter when fewer samples are taken because classes can be easily identified in the LULC maps which can be post validated off the field. Heterogeneous samples for savannah, shrub-land, and grassland required many sample points for verification of the tree canopy cover, tree height, leave type and health on the ground because features are different.

\subsubsection{Change analysis using post classification:}

Terrset software based Land Change Modeller (LCM) was used for seasonal land use-land cover change detection of two LANDSAT images for 2014 during dry and rainy season and modelling land degradation by water susceptibility using post classication technique. Post classification technique of two images will be accurate as the accuracies of each LULC maps (see Figure $4 \& 5$ ).

\begin{tabular}{|l|l|l|l|l|l|}
\hline Class Name & $\begin{array}{l}\text { Reference } \\
\text { Totals }\end{array}$ & $\begin{array}{l}\text { Classified } \\
\text { Totals }\end{array}$ & $\begin{array}{l}\text { Number } \\
\text { Correct }\end{array}$ & $\begin{array}{l}\text { Producers } \\
\text { Accuracy }(\%)\end{array}$ & $\begin{array}{l}\text { Users Accuracy } \\
(\%)\end{array}$ \\
\hline Water body & 20 & 20 & 18 & 90 & 90 \\
\hline Bare land & 20 & 20 & 18 & 90 & 90 \\
\hline Mining area & 22 & 22 & 22 & 100 & 100 \\
\hline Cropland & 20 & 20 & 20 & 100 & 100 \\
\hline Forest & 9 & 10 & 7 & 78 & 70 \\
\hline Savannah & 29 & 30 & 24 & 83 & 80 \\
\hline Shrub land & 31 & 30 & 25 & 81 & 83 \\
\hline Grass land & 31 & 30 & 24 & 79 & 80 \\
\hline Village & 10 & 10 & 10 & 100 & 100 \\
\hline Rocky Outcrop & 10 & 10 & 10 & 100 & 100 \\
\hline
\end{tabular}

Table 1: Accuracy assessment of the 2014 dry season land use-land cover map

Total samples $=202$

Number correct $=178$
Overall Classification Accuracy $=178 / 202=$

$88.12 \%$

Overall kappa statistics $=0.8751$

\begin{tabular}{|l|l|l|l|l|l|}
\hline Class Name & $\begin{array}{l}\text { Reference } \\
\text { Totals }\end{array}$ & $\begin{array}{l}\text { Classified } \\
\text { Totals }\end{array}$ & $\begin{array}{l}\text { Number } \\
\text { Correct }\end{array}$ & $\begin{array}{l}\text { Producers } \\
\text { Accuracy }(\%)\end{array}$ & $\begin{array}{l}\text { Users Accuracy } \\
(\%)\end{array}$ \\
\hline Water body & 20 & 20 & 20 & 100 & 100 \\
\hline Bare land & 20 & 20 & 16 & 80 & 80 \\
\hline Mining area & 24 & 24 & 24 & 100 & 100 \\
\hline Cropland & 20 & 20 & 20 & 100 & 100 \\
\hline Forest & 7 & 10 & 7 & 100 & 70 \\
\hline Savannah & 33 & 30 & 22 & 67 & 73 \\
\hline Shrub land & 32 & 30 & 22 & 69 & 73 \\
\hline Grass land & 28 & 30 & 23 & 83 & 77 \\
\hline Village & 10 & 10 & 10 & 100 & 100 \\
\hline Rocky Outcrop & 10 & 10 & 10 & 100 & 100 \\
\hline
\end{tabular}

Table 2: Accuracy assessment of the 2014 rainy season land use-land cover map 
Total samples $=204$

Number correct $=174$
Overall Classification Accuracy $=174 / 204=85.29 \%$

Overall kappa statistics $=0.8455$

\section{RESULTS}

\subsection{Seasonal LULC and land degradation susceptibility}

Seasonal variation in LULC types was derived from the dry and rainy season land use-land cover maps in Figure 2 $\& 3$.

Seasonal LULC results of 2014 for Palapye region are shown in Figures 2 and 3 as maps and bar charts. These figures show the spatial distribution and the share of land under LULC classes for Level I measured in kilometre squared. The overall accuracy of these maps are $88.12 \%$ and $85.29 \%$ and kappa statistics are 0.8751 and 0.8455 for dry and rainy season respectively. The overall accuracy of these seasonal LULC maps meets the threshold set by the USGS because they are all above 75\% (RCMRD-SERVIR Africa, 2013).

Results of the dry season LULC map of 2014 are stated in percentages for Level I. The share of land under each LULC class according to the level I results are arranged from high to low land cover percentage as follows: savannah (30\%), shrub land (27\%), grassland (19.9\%), paved/rocky material $(9.5 \%)$, bare land $(6 \%)$, cropland (5.5\%), built-up area $(1.6 \%)$, water body $(0.31 \%)$, mining area $(0.07 \%)$, and forest $(0.007 \%)$

Similarly, results of the rainy season LULC map of 2014 are arranged from highest to lowest spatial extent: Level I results reveal that savannah registered the highest percentage share of land with $30 \%$, shrub land (28.4\%), grassland $(20 \%)$, paved/rocky material $(9 \%)$, cropland $(5.5 \%)$, bare land $(5 \%)$, built-up area $(1.6 \%)$, water body $(0.33 \%)$, mining area $(0.07 \%)$ and forest $(0.007 \%)$.

There was no variation in the following seasonal land useland cover classes in terms of spatial extent: Savannah (30\%), Cropland (5.5\%), Built-up area (1.6\%), Mining area $(0.07 \%)$ and Forest $(0.007 \%)$.

However, a slight increase in rainy season land use-land cover variation was experienced in Shrub land by $1.4 \%$ from $27 \%$, Grass land by $0.1 \%$ from $19.9 \%$, and Water body by $0.02 \%$ from $0.33 \%$, whereas there was slight decrease in paved/rocky material by $0.5 \%$ from $9.5 \%$ and bare land by $1 \%$ from $6 \%$ in dry season.

The results suggest that about $985 \mathrm{~km}^{2}(22 \%)$ of the study area is susceptible to LD by water, major LULC types affected include: cropland (5.5\%), paved/rocky material $(9.5 \%)$, bare land $(6 \%)$, built-up area $(1.6 \%)$, mining area $(0.07 \%)$, and water body $(0.33 \%)$. Land degradation by water susceptibility due to seasonal land use-land cover variations is high in the east of the study area (see Figure $6)$.

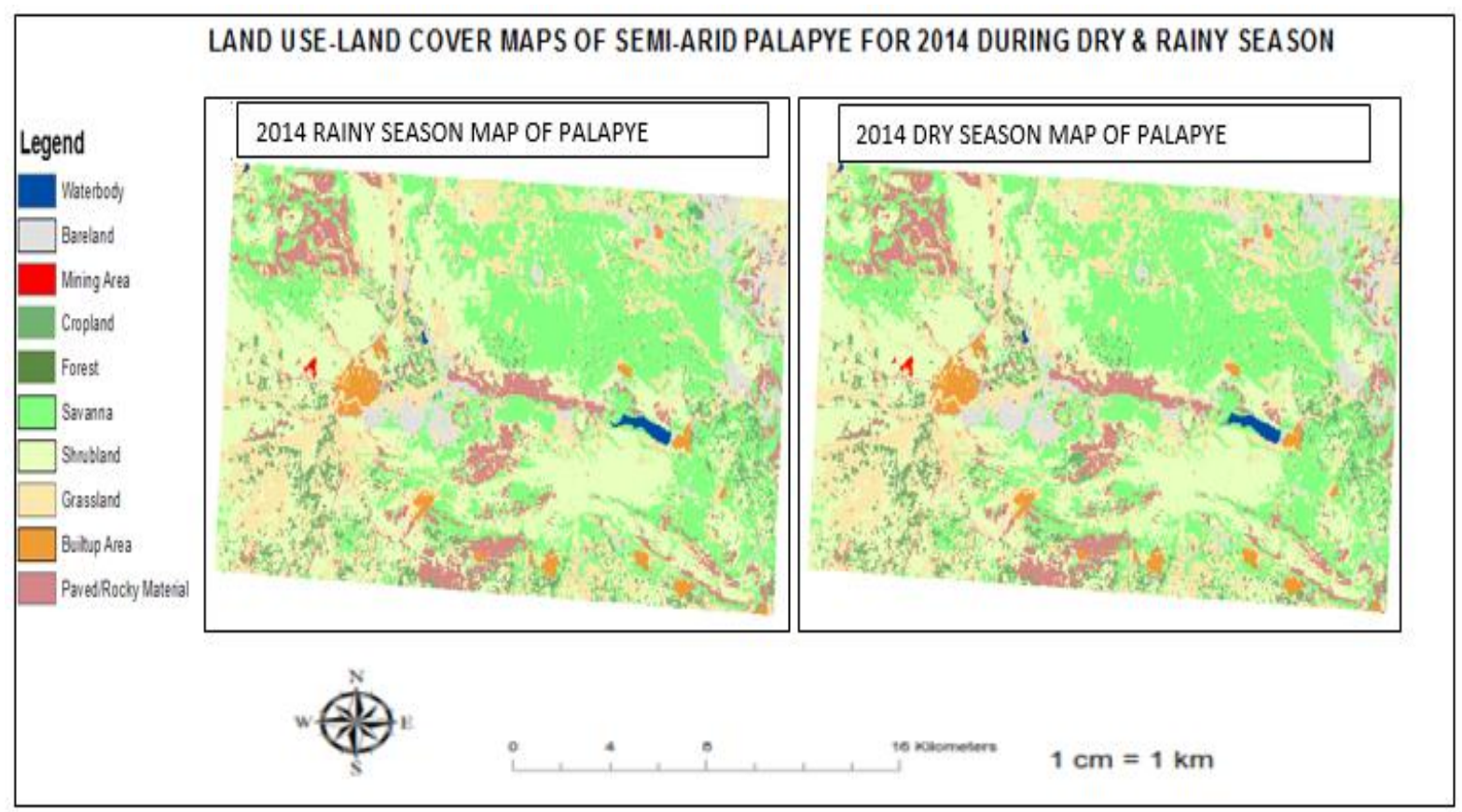

Figure 2: Seasonal land use-land cover maps of semi-arid Palapye for 2014 dry and rainy season. 

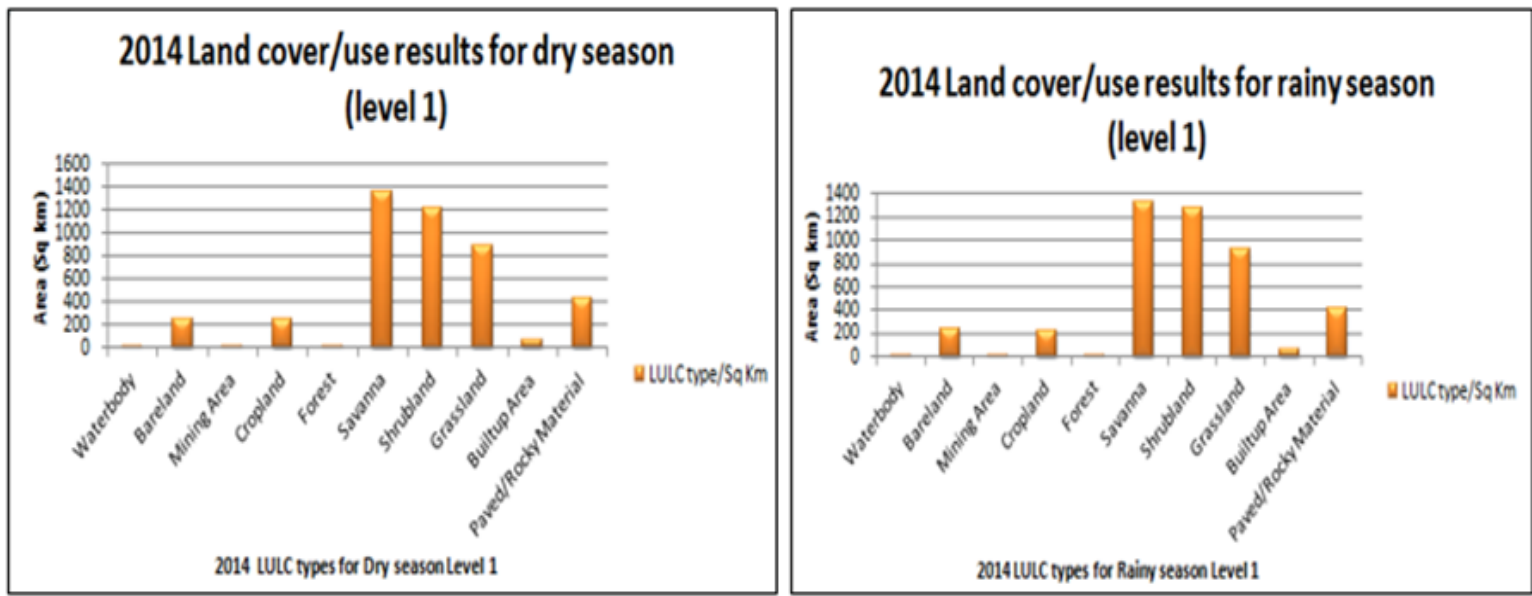

Figure 3: Seasonal land use-land cover bar charts for semi-arid Palapye in 2014 dry and rainy season.

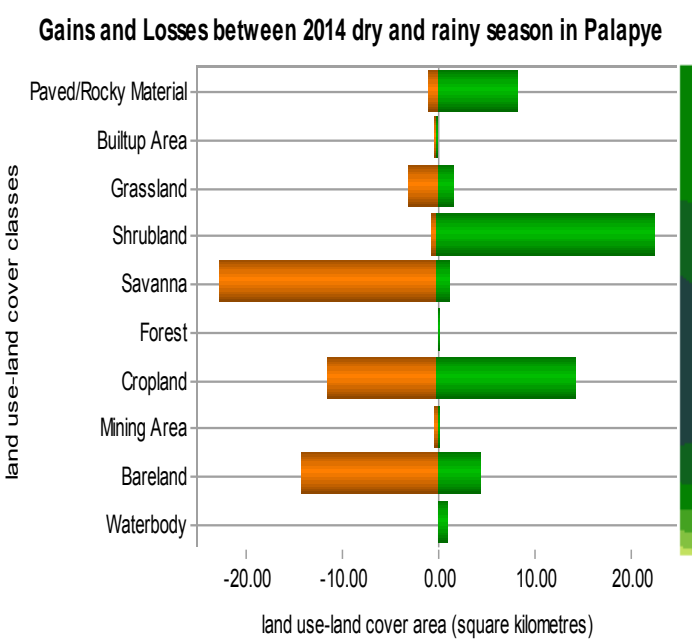

Figure 4: Gantt chart showing the gains and losses of LULC types between dry and rainy season in 2014 in Palapye.

\section{DISCUSSION}

Major LULC classes at Level I were identified and mapped for the dry and rainy season (see Figure $2 \& 3$ ). Seasonal variations in LULC types was examined by gains and losses as shown in Figure 4. Land use-land cover and land degradation by water linkage was established as shown in Figure 5 by LULC classes which converted into bare land during dry season.

\subsection{Seasonal variations in Land Use-Land Cover}

Palapye area is an example of a land degradation by water prone area in Botswana as supported by the following environmental and anthropogenic factors: semi-arid climate, low rainfall of $250 \mathrm{~mm}-650 \mathrm{~mm}$ per year, torrential downpours of short interval which are very erosive in nature, high temperatures in summer which result in high evaporation and plant transpiration, very steep watershed topography (Department of Meteorological Services, 2015).

\subsection{Land Use-Land Cover Change as a factor of LD}

The highest seasonal land use-land cover variation was experienced in bare land from rainy to dry season recording $1 \%$ increase and most exchanges occurred in

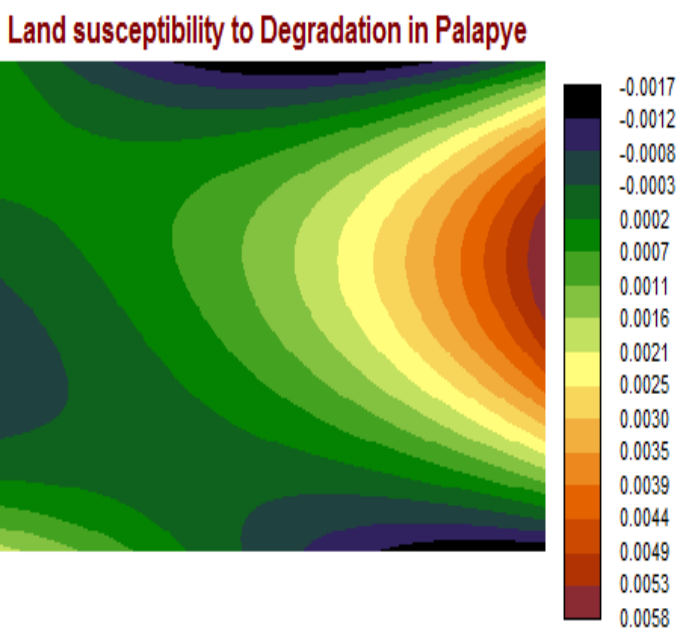

Figure 5: Land susceptibility to degradation is highest in the east of Palapye.

cropland i.e. many croplands converted into bare land in dry season. This makes croplands highly susceptible to land degradation by rainfall splash and runoff. The least seasonal land use-land cover variation was recorded in water body in 2014 and this is attributed to the semi-aridity of the study region. Most of the top soil exposure in semiarid regions is due to the LULC practises such as overgrazing, agricultural intensification, deforestation and mining around the world (Utuk and Daniel, 2015). These LULC practises account for 16-40\% of farmlands already exposed to LD in Sub Saharan Africa countries, which is high (Chappell and Lavalle, 2011) as 22\% LULC classes are vulnerable to LD in the study area.

There are many factors of LD driven by LULC change in the study area such as overstocking, overgrazing, inappropriate ploughing methods, continuous mining and leaching of nutrients, absence of conservation methods, cultivation of poor structured soils on steep slopes, (Moroke and Patrick, 2015). (see Figure 6).

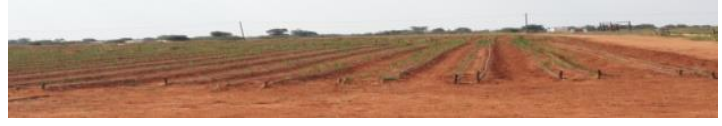

Figure 6: Horticultural farm in Dikabeya - The top soil is susceptible to soil erosion by water as a result of artificial rills and gullies created. 


\subsection{Implications of observed Seasonal Land Use-Land Cover Variation on LD}

Poor LULC practises in semi-arid regions result in land susceptibility to degradation, especially soil degradation. With the onset of degradation, the productive quality of the land is lost over time, thus reducing the chances of attaining food security in the future. As many countries are increasing in population, demand for land to provide food, shelter and fibre is also increasing. In the process, vegetated areas are replaced by cultivated lands due to human activities which increase exposure of top soils. Over time, an impact of top soil exposure is the loss of organic matter content due to topsoil rainfall runoff hence reducing soil fertility and crop yield (Utuk and Daniel, 2015).

\subsection{Next Steps}

Results from this study have laid the ground work for examining the susceptibility of land to LD based on seasonal variation in LULC in this semi-arid environment. A link between LULC type and LD susceptibility is suggested, which would require further examination. Therefore, next on our research agenda is to assess and quantify historical changes in LULC patterns in Palapye. On the basis of the rates and trends of observed land change, changes in LULC in the future can be projected. By examining the dynamics of LULC, we hope to better identify the principal signals of observed change and driving factors for Palapye. Also, we would like to examine the impact of LULC change on other types of land degradation. For example, modelling the physical and chemical properties of soil such as organic matter content and texture, topography, erosive nature of rainfall, temperature, vegetation cover by using Normalized Difference Vegetation Index (NDVI), conservation factor, livestock and human population as factors of soil erosion by water. These inputs would aid in refining the assessment of land susceptibility to LD in this context.

\section{CONCLUSION}

Assessment of LULC and LD linkage is not an easy task due to the complexity of the numerous drivers at play and various methods are used including expert assessment, modelling and remote sensing. In this remote sensing based study, seasonal LULC types and changes occurring in the study area were identified, mapped and assessed as a factor of LD by water as shown in Figure 2-5. It was found that $22 \%$ of bare land exists in semi-arid Palapye region computed from the sum of the major LULC classes: cropland (5.5\%), paved/rocky material $(9.5 \%)$, bare land $(6 \%)$, built-up area $(1.6 \%)$, mining area $(0.07 \%)$, and water body $(0.33 \%)$. Land degradation by water susceptibility due to seasonal land use-land cover variations is highest in the east of Palapye where there is high cropland to bare land conversion creating a major linkage. Due to the land management practices observed during field work, majority of lands under these LULC classes are made up of bare land and are not protected from degradation by water. Increased bare land exposure during dry season from the contributing LULC classes above creates a linkage between LD by water and seasonal LULC variation because topsoil is increasingly exposed to rainfall splash and runoff in farmlands. As this study is only focused on a year, there is need to assess changes in
LULC over a longer period, i.e. from the past to the present, to better examine its implications for land degradation. Future projection of LULC change, especially with a focus on analysing the LULC classes with the highest probabilities of being converted into bare land is required.

\section{ACKNOWLEDGEMENTS}

The research reported in this paper was conducted under the auspices of the Monitoring land degradation in the Central District of Botswana: A three-tier land degradation index mapping approach LDIMapping project, funded by the United States Agency for International Development (USAID) through the RCMRD/SERVIR-Africa Small Grants Program (Grant number: SERVIR/E\&S/2014/004) and co-funded by the Botswana International University of Science and Technology (BIUST). The research permit granted by the Government of Botswana is acknowledged. Any opinions, expressed in this article are those of the authors and do not reflect those of the funders.

\section{REFERENCES}

Barrow, C.J., 1991. Land Degradation: Development and Breakdown of Terrestrial Environments. Cambridge University Press, Cambridge.

Bhattarai, B., 2013. Sediment Transport Modeling Using GIS in Bagmati Basin, Nepal. Sediment Transport Processes and Their Modelling Applications, Dr. Andrew Manning (Ed.), InTech, DOI: 10.5772/51449.

Botswana Guardian, 2014. Palapye Economy: boom or bust? Botswana Guardian, Gaborone. Available online at http://www.botswanaguardian.co.bw/northernextra/item/856-palapye-economy-boom-or-bust.html (Accessed 27 November 2015).

Brown, D., Delgado, A., Moss, R., Sedano, F., 2015. Need and Options for Subnational Scale Land-Use and Land Cover Scenarios for the United States.U.S Global Change Program. http ://data. globalchange. gov/ report/usgcrp-need-options-subnational scale-land-useland-cover-scenarios-united-states (Accessed 26 November 2015).

Chappell, M.J and Lavalle, L.A., 2009. Food security and biodiversity: can we have both? Agriculture and Human Values, 28, pp. 3-26. Available online at http://www. springerlink. com/ openurl.asp?genre $=$ article $\& \mathrm{id}=\mathrm{doi}$ : 10.1007/ S10460-10009-19251-4(Accessed 27

November 2015).

Chen, J., Chen, J., Liao, A., Cao, X., Chen, L., Chen, X., He, C., Han, G., Peng, S., Lu, M., Zhang, W., Tong, X., Mills, J., 2015. Global land cover mapping at $30 \mathrm{~m}$ resolution: A POK-based operational approach. ISPRS Journal of Photogrammetry and Remote Sensing 103:pp. $7-27$.

Deka, J., Tripathi, O.P.,Khan, M.L., 2014. Study on Land Use/Land Cover Change Dynamics through Remote Sensing and GIS - A Case Study of Kamrup District, North East India. Journal of Remote Sensing \& GIS, 5(1), pp.55-62. 
Favretto, N., Stringer, L.C., Dougill, A.J., Perkins, J.S., Akanyang, L., Dallimer, M., Atlhopheng, J.R., Mulale, K., 2014. Assessing the socio-economic and environmental dimensions of land degradation: A case study of Botswana's Kalahari. Report for the Economics of Land Degradation Initiative. Leeds, UK, 28 pg. (accessed 17 June 2015) http://www.see.leeds.ac.uk/research/sri/eld/

French Scientific Committee on Desertification, 2005. Remote sensing: a tool to monitor and assess desertification. Les dossiers thematiques $d u C S F D$, Issue 2. ISSN: 1772-6964, Montpellier, France.

Food and Agriculture Organization, 2015. World deforestation slows down as more forests are better managed.www.fao.org/news/story/en/item/326911/icode (accessed 26 November 2015)

GISGeography, 2015. Image Classification Techniques in Remote Sensing. http://gisgeography.com/imageclassification-techniques-remote-sensing/ (accessed 26 November 2015).

Global Forest Resources Assessment., 2015. How are the world's forests changing. FAO Forestry, Rome,Italy, ISBN: 978-92-5-108821-0. www.fao.org/forestry/fra.

Hansen, M.C., Potapov, P.V., Moore, R., Hancher, M., Turubanova, S.A., Tyukavina, A.,Thau, D., Stehman, S.V., Goetz, S.J., Loveland, T.R., Kommareddy, A., Egorov, A., Chini, L., Justice, C.O., Townshend, J.R.G., 2013. High-resolution global maps of 21st-century forest cover change. Science 342 (15), pp. 851-853. Available online at https://www.researchgate.net/publication/ 262734548_High-Resolution_Global_Maps_of_21stCentury-Forest_Cover_Change (Accessed 27 November 2015).

International Atomic Energy Agency, 2014. Impact of Soil Conservation Measures on Erosion Control and Soil Quality.Vienna International Centre, Vienna, Austria, Available online at www-pub.iaea.org/pdf/te_1665_web (accessed 26 November 2015).

Kairis, Or., Kosmas, C., Karavitis, Ch., Ritsema, C., Salvati, L., Acikalin, S., Alcalá, M., Alfama, P., Atlhopheng, J., Barrera, J., Belgacem, A., Solé-Benet, A., Brito, J., Chaker, M., Chanda, R., Coelho, C., Darkoh, M., Diamantis, I., Ermolaeva, O., Fassouli, V., Fei, W., Feng, J., Fernandez, F., Ferreira, A., Gokceoglu, C. and Gonzalez, D. and Gungor, H. and Hessel, R., Juying, J., Khatteli, H., Khitrov, N., Kounalaki, A., Laouina, A., Lollino, P., Lopes, M., Magole, L., Medina, L., Mendoza, M., Morais, P., Mulale, K., Ocakoglu, F., Ouessar, M., Ovalle, C., Perez, C., Perkins, J., Pliakas, F., Polemio, M., Pozo, A., Prat, C., Qinke, Y., Ramos, A., Ramos, J., Riquelme, J., Romanenkov, V., Rui, L., Santaloia, F., Sebego, R., Sghaier, M., Silva, N., Sizemskaya, M., Soares, J., Sonmez, H., Taamallah, H., Tezcan, L., Torri, D., Ungaro, F., Valente, S., de Vente, J., Zagal, E., Zeiliguer, A., Zhonging, W., Ziogas, A., 2014. Evaluation and Selection of Indicators for Land Degradation and Desertification Monitoring: Types of Degradation, Causes, and Implications for Management. Environmental Management 54(5): 1 pp. 971-982. http://dx.doi.org/10.1007/s00267-013-0110-0.
Kuldeep, T., Kamlesh, K., 2011. Land use/land cover change detection in Doon valley (Dehradun Tehsil), Uttarakhand, using GIS and Remote Sensing technique. Inter Journal of Geomatics and geosciences 2(1),pp. 3441.

Li, Z., Deng, X., Yin, F., Yang, C., 2015. Analysis of climate and land use changes impacts on land degradation in the north China plain, Advances in Metereology, Article ID 976370, 11 pages, http://dx.doi.org/10.1155/2015/976370.

Magee, K.S., 2011. Segmentation, object-oriented applications for remote sensing land cover and land use classification. Doctoral dissertation, University of Cincinnati, USA.

Mirzabaev, A, J. Goedecke, O. Dubovyk, U. Djanibekov, Q. B. Le and A. Aw-Hassan, 2016. Economics of Land Degradation in Central Asia. In E. Nkonya, Mirzabaev, A, and Joachim von Braun (eds.), Economics of Land Degradation and Improvement: A Global Assessment for Sustainable Development, 261-290, Switzerland: Springer. DOI 10.1007/978-3-319-19168-3_10.

Mohammed, Y.H., 2013. The influence of land use and cover changes on the pastoral rangeland systems of southern Ethiopia- How much woody cover is enough. $\mathrm{PhD}$ Dissertation of the University of Hohenheim. Stuttgart, Germany. http://opus.unihohenheim.de/volltexte/2014/971/.

Murayama, Y., Estoque, R.C., Subasinghe, H., Hou, H. and Gong, H. 2015. Land-use/land-cover changes in major Asian and African cities. Annual Report on the Multi Use Social and Economic Data Bank. Scientific Research Publishing Inc.USA 92, pp.11-58.

Olagunju, T.E., 2015. Drought, desertification and the Nigerian environment: A review, Ibadan, Nigeria.

Puertas, O.L., Brenning, A., Meza, F.J., 2013. Balancing misclassification errors of land cover classification maps using support vector machines and Landsat imagery in the maipo river basin (Central Chile, 1975-2010). Remote Sensing of Environment, 137:pp.112-123.

RCMRD-SERVIR Africa, 2013. Land cover mapping for green house gas inventories development project in East and Southern Africa. Training date 10-14 March 2014, Nairobi, Kenya.

Statistics Botswana, 2014. Population and Housing Census 2011 Analytical Report, Gaborone, Botswana. http://www.cso.gov.bw/images/analytical_report.pdf (Accessed 26 November 2015).

Union of Concerned Scientists, 2015. UCS Satellite Database. http://www. ucsusa. org/nuclear-weapons/spaceweapons/satellite-database.html\#.VlbpSL_wwrE (accessed 26 November 2015).

Utuk, I.O and Daniel, E.E., 2015. Land degradation: A threat to food security: A global assessment, Journal of Environment and Earth Science, 5(8), pp. 13-21. ISSN 2225-0948(online). 